\title{
Numerical Simulation of Meandering Effects on Velocity Field and Separation Zone past a Spur Dike in Rigid Bed
}

\author{
Mukesh Raj Kafle a \\ a Department of Civil Engineering, Pulchowk Campus, Institute of Engineering, Tribhuvan University, Nepal \\ Corresponding Email: ${ }^{a}$ mkafle@pcampus.edu.np
}

\begin{abstract}
This study presents a numerical model to simulate two-dimensional flow field near a vertical impermeable spur dike in a sine-generated rigid bed meandering channel. Comprehensive study of resultant velocity and separation zone past the spur dike on five different channels with meandering angles $0^{\circ}, 15^{\circ}, 30^{\circ}, 45^{\circ}$ and $60^{\circ}$ were carried out and compared. The CFD model Nays 2D was used to simulate the flow field. CubicInterpolated Pseudo-Particle (CIP) method was used as finite difference method to analyze the advection terms. The study reveals that unlike straight channel, flow field and separation zone past the spur dike are influenced by the position of spur dike and angle of meandering. For meandering angle equal or greater than $60^{\circ}$ and position of spur dike at $\mathrm{s}^{*}=0.5$ with reference to the straight rectangular channel from the upstream end on the right bank, significance of spur dike as a flow deflector does not prevail. With the same flow parameters and channel characteristics, the velocity amplification is maximum to angle of meandering equal to $30^{\circ}$.
\end{abstract}

\section{Keywords}

CFD, numerical model, meandering channel, separation zone, spur dike, rigid bed

\section{Introduction}

Spur dikes are hydraulic structures extending from the bank of a stream to the main flow direction. Main purpose of providing such structures is river training and erosion protection of the riverbank. Requirement of river constriction and desired constricted depth usually determine spur dike length (Richardson et al., 1975; USACE, 1980). The spacing between spur dikes is usually taken to be a function of the spur dike length Brown (1984). The relation of spur dike orientation to the main flow direction substantially affects the flow pattern adjacent to the spur dike.

The flow pattern in the vicinity of a single unsubmerged spur dike forms four main zones. They are - the main flow zone, return flow zone, shear layer and reattachment point (Fei-Yong and Ikeda, 1997; Yossef and Klaassen, 2002). The main flow zone comprises the region between the spur dike tip and the opposite channel wall. The return flow zone is also termed as the recirculation area, eddy zone or dead zone. It is located downstream in the lee of the spur dike between the flow separation streamline and the right wall of the channel (viewing downstream). A shear layer between the two zones is developed with difference in the flow velocities in the return zone and the main flow zone (Rajaratnam and Nwachukwu, 1983). Some distance downstream the spur dike, the separation streamline attaches to the channel sidewall at the reattachment point. Spur dike type, contraction ratio, aspect ratio, channel characteristics and numerous flow parameters govern flow structure around and flow separation zone past a spur dike in a channel. The contraction ratio represents ratio of groyne length to river width whereas aspect ratio means the ratio of groyne spacing to groyne length. A number of researchers have studied the flow field and flow separation zone due to a spur dike in a straight rectangular channel with rigid bed (Rajaratnam and Nwachukwu, 1983; Ettema and Muste, 2004) and numerically (Tingsanchali and Maheswaran, 1990; Molls et al., 1995; Ouillon and Dartus, 1997). In addition, researchers have carried out some numerical studies to analyze the flow field near a spur dike on a mobile bed (Nagata et al., 2005; Koken and Constantinescu, 2008; Koken, 2011). A few studies for flow past spur dike(s) in a meandering channel are also reported. Giri et al. (2004) discussed details of 
the separation zone near a spur dike in a meandering channel. Sharma and Mohapatra (2009) studied effect of location of the spur dike in a sine-generated channel with a trapezoidal cross section. Moreover, Sharma and Mohapatra (2012) carried out a study on detailed description of the separation zone for flow past a spur dike in a meandering channel. To the author's knowledge, effect of meandering angle on flow field along stream wise and cross- stream of a channel is missing. In this context, the main objective of this study is to present numerically effects of meandering angle on the velocity field and separation zone past a perpendicular impermeable spur dike in a rigid bed sine-generated channel.

\section{Model}

The Computational Fluid Dynamics (CFD) model selected for this study was NAYS 2D (iRIC 2.0) which is an analytical solver for calculation of unsteady two-dimensional plane flow and river bed deformation using boundary fitted coordinates within general curvilinear coordinates. Among the finite difference method; CIP method was applied to the advection terms in equation of motion. For the turbulent field calculation due to its superiority, $k-\varepsilon$ model was applied. The governing equations used in the model are

\section{Continuity equation}

$$
\frac{\partial h}{\partial t}+\partial \frac{(h u)}{\partial x}+\partial \frac{(h u)}{\partial y}=0
$$

Momentum equations in $\mathbf{x}$ - and $\mathbf{y}$ - directions

$$
\frac{\partial(u h)}{\partial t}+\frac{\partial\left(h u^{2}\right)}{\partial x}+\frac{\partial(h u v)}{\partial y}=-g h \frac{\partial H}{\partial x}-\frac{\tau_{x}}{\rho}+D^{x}+\frac{F_{x}}{P}
$$

In which

$$
\begin{aligned}
& \frac{\tau_{x}}{\rho}=C_{f} u \sqrt{u^{2}+v^{2}}, \quad \frac{\tau_{y}}{\rho}=C_{f} v \sqrt{u^{2}+v^{2}} \\
& D^{x}=\frac{\partial}{\partial x}\left[v_{t} h \frac{\partial u}{\partial x}\right]+\frac{\partial}{\partial y}\left[v_{t} h \frac{\partial u}{\partial y}\right] \\
& \frac{F_{x}}{\rho}=\frac{1}{2} C_{D} \alpha_{s} h_{v} u \sqrt{u^{2}+v^{2}} \\
& \frac{F_{y}}{\rho}=\frac{1}{2} C_{D} \alpha_{s} h_{u} u \sqrt{u^{2}+v^{2}}
\end{aligned}
$$

Where,

$$
\begin{aligned}
& h=\text { water depth } \\
& t=\text { time }
\end{aligned}
$$

$u, v=$ depth averaged velocities in $x$ and $y$ directions

$$
g \text { = gravitational accelerations, } H=\text { water depth }
$$

$\tau_{x}, \tau_{y}=$ components of shear stress in river bed in $x$ and $y$-directions

$F_{x}, F_{y}=$ components of drag force by vegetation in $x$ and $y$-directions

$C_{f}=$ drag coefficient of the bed shear stress

$v_{t}=$ eddy viscosity coefficient

$C_{D}=$ drag coefficient of vegetation

$\alpha_{s}=$ area of interception by vegetation per unit volume

$h_{v}=$ minimum value of water depth and height of vegetation

For validation, the model was applied to the flow near a spur dike in a fixed bed straight rectangular channel. The computational conditions used herein were the same as the ones in case A1 in Rajaratnam and Nwachukwu (1983) experiment. The computed results satisfactorily agreed with the observed results from experiment by Rajaratnam and Nwachukuwa. The computed results prove that Nays 2D was capable of solving numerically and analyze the flow field near a spur dike. The validated model was then applied for the present study.

In the present study, for numerical simulation, a sinegenerated channel $4 \mathrm{~m}$ long and $0.9 \mathrm{~m}$ wide was created. The spur dike having length of $0.15 \mathrm{~m}$ and thickness $0.02 \mathrm{~m}$ was located vertically on the right bank $2 \mathrm{~m}$ $\left(\mathrm{s}^{*}=0.5\right)$ downstream from the upstream end. The computational grid of size $0.02 \mathrm{~m} \times 0.03 \mathrm{~m}$ along the stream wise and cross- stream directions respectively were generated. The discharge was taken as 0.0175 $\mathrm{m}^{3} / \mathrm{s}$ similar to Rajaratnam and Nwachukwu (1983) experiment. To ensure smooth flow, upstream and downstream portions were added with straight reaches $1 \mathrm{~m}$ and $0.5 \mathrm{~m}$ of same width respectively. For boundary conditions, water surface at downstream and velocity at upstream were considered as uniform flow. Slope for uniform flow was calculated from geographical data. The numerical simulation was carried out for a rectangular channel various angle of meandering $0^{\circ}$, $15^{\circ}, 30^{\circ}, 45^{\circ}$ and $60^{\circ}$. The channel bed was fixed with Manning's Roughness Coefficient 0.02 . 


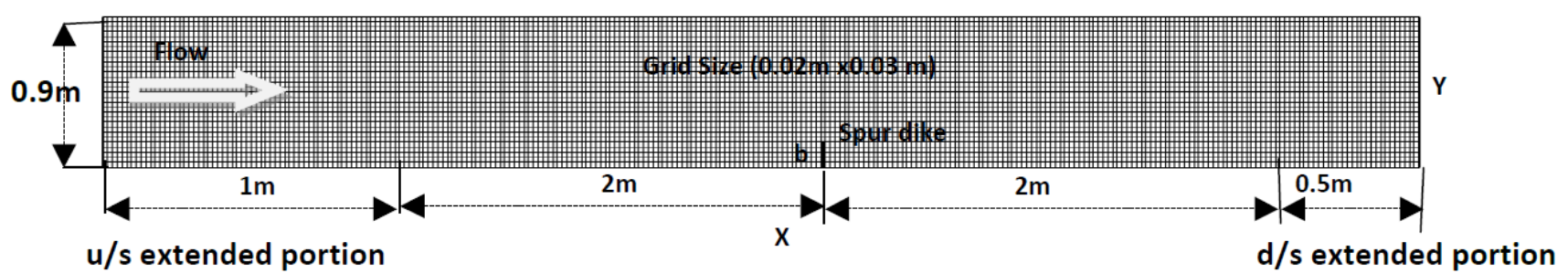

Time: 100500

Figure 2.1: Numerically Created Channel

\section{Results and Discussion}

The present study takes into account five different cases to evaluate the effects of meandering angle to velocity field and separation zone in rigid bed.

\subsection{Resultant Velocity (U/U0)}

Resultant velocity around the influenced zone by spur dike are plotted graphically and analyzed. For each case, starting from the nose of the spur dike $(\mathrm{x} / \mathrm{b}=0)$ resultant velocity from $x / b=-6$ (upstream of the structure) to $\mathrm{x} / \mathrm{b}=10$ (downstream of the structure) along stream wise direction and from $y / b=1$ to 4 along cross stream direction where velocity field is presumed to be influenced due to presence of spur dike are taken into consideration for analysis.

At $y / b=1.0$, considering the base value for straight channel i.e meandering angle $=0^{\circ}$, the resultant velocity almost follows the same trend for meandering angle $15^{\circ}, 30^{\circ}$ and $45^{\circ}$ both qualitatively and quantitatively having its value less than unity along upstream of spur dike. Whereas, for meandering angle $60^{\circ}$ the trend is quite different unlike rest of four conditions. All values of resultant velocity at upstream are greater than unity and shows instability. At the nose of structure, in case of meandering angle $0^{\circ}$ and $15^{\circ}$, resultant velocity is less than unity having its value around 0.6 . For meandering angle $30^{\circ}$ that value is greater than unity whereas for meandering angle $45^{\circ}$, resultant velocity equals to unity. In contrast, for meandering angle $60^{\circ}$, at the nose of the structure resultant velocity tends to zero. At the downstream of the structure within the separation zone resultant velocity indicates the same trend with slight difference in numeric values for meandering angles $0^{\circ}, 15^{\circ}, 30^{\circ}$ and $45^{\circ}$. However, in case of meandering angle $60^{\circ}$, the trend of resultant velocity is quite opposite to the rest cases indicating no any effects of spur dike at that position (Figure 3.1).

At $y / b=2.0$, along upstream side of the spur dike the resultant velocity has almost same value except for meandering angle $45^{\circ}$ having values slightly at lower side. At downstream side, considering resultant velocity for meandering angle $0^{\circ}$ as base value, resultant velocity for meandering angle $15^{\circ}$ has the same trend and magnitude. In case of meandering angle $30^{\circ}$ up to stream wise direction $x / b=3.0$ has the same value with meandering angle $0^{\circ}$ and $15^{\circ}$ From $\mathrm{x} / \mathrm{b}=3.0$ to 7.0 , the resultant velocity drops significantly. Beyond $\mathrm{x} / \mathrm{b}=7.0$, again almost coincides with values of $0^{\circ}$ and $15^{\circ}$. The resultant velocity downstream of spur dike for meandering angle $45^{\circ}$ up to $\mathrm{x} / \mathrm{b}=7.0$ has the same trend with meandering angle $30^{\circ}$ having its value at lower side. However, beyond $\mathrm{x} / \mathrm{b}=7.0$, the resultant velocity shows its contrast nature with rising trend unlike previous conditions i.e in case of meandering angle $0^{\circ}, 15^{\circ}$ and $30^{\circ}$. Moreover, while the meandering angle equals $60^{\circ}$, the resultant velocity doesn't follow any trend showing no effect of spur dike to velocity field at that position (Figure 3.2).

At $y / b=3.0$, either upstream and downstream portion, resultant velocity for all cases of meandering angle $0^{\circ}$, $15^{\circ}$ and $30^{\circ}$ have almost the same magnitudes and trends. In case of meandering angle $45^{\circ}$ and $60^{\circ}$ at upstream portion resultant velocity has the same characteristics both in magnitude and trends with previous cases. However in downstream portion no any effects of spur dike up to $\mathrm{x} / \mathrm{b}=8.0$ are observed (Figure 3.3).

Likewise, at $\mathrm{y} / \mathrm{b}=4.0$ similar conditions as in the case of $y / b=3.0$ prevails (Figure 3.4 ). 


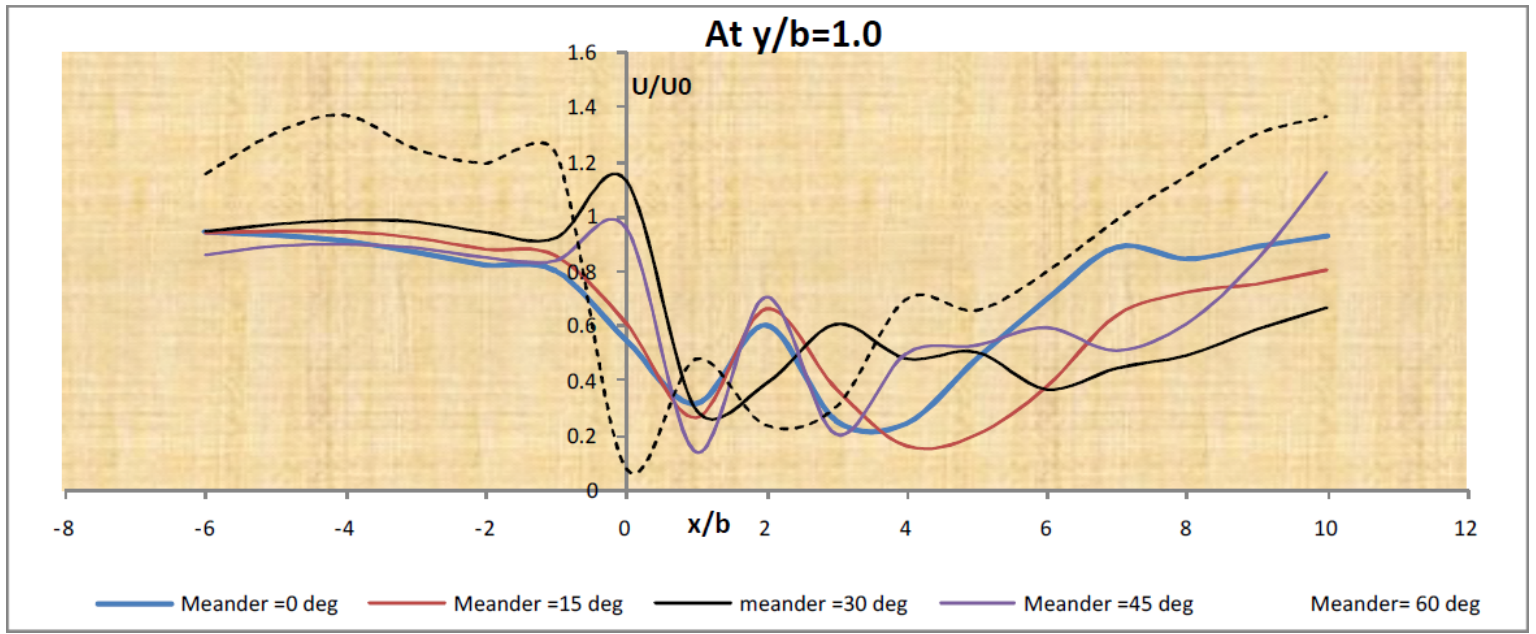

Figure 3.1: Resultant Velocity Profile at $\mathrm{y} / \mathrm{b}=1.0$

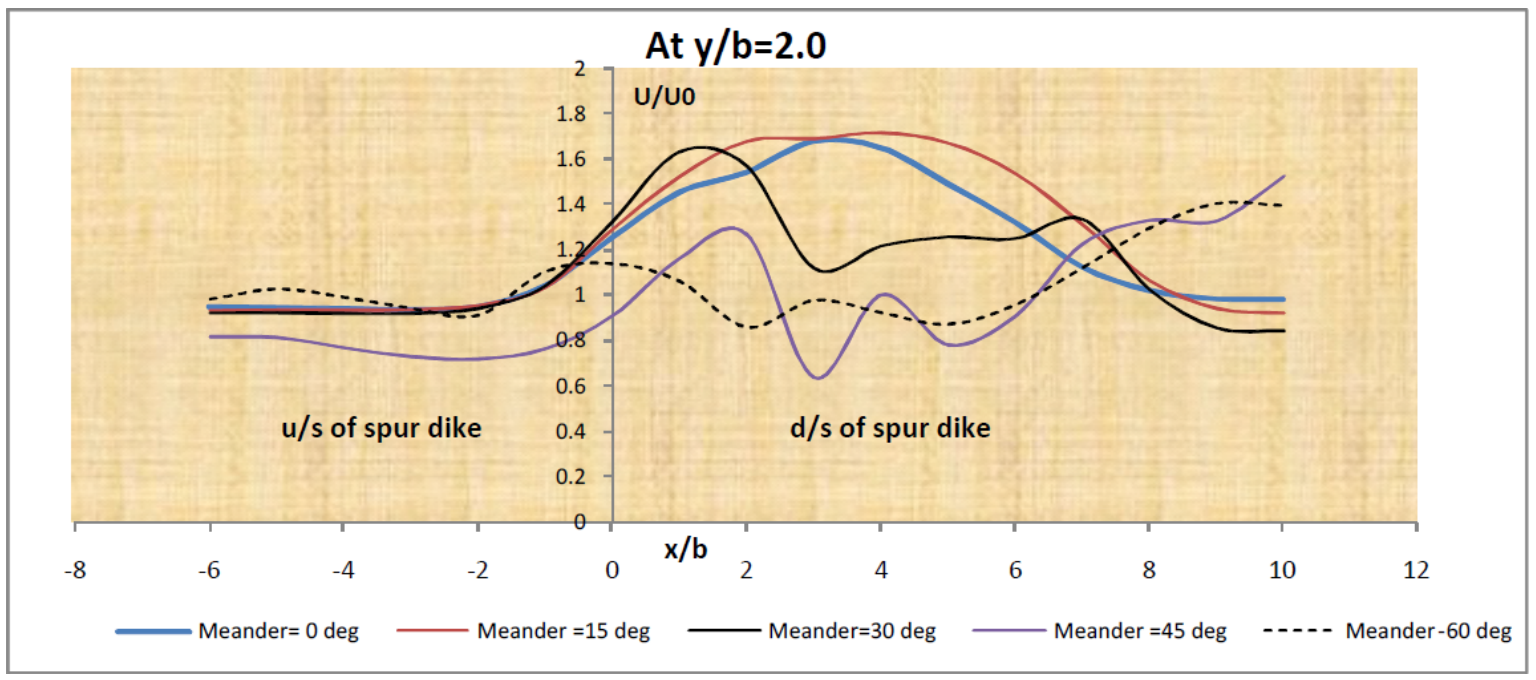

Figure 3.2: Resultant Velocity Profile at $y / b=2.0$

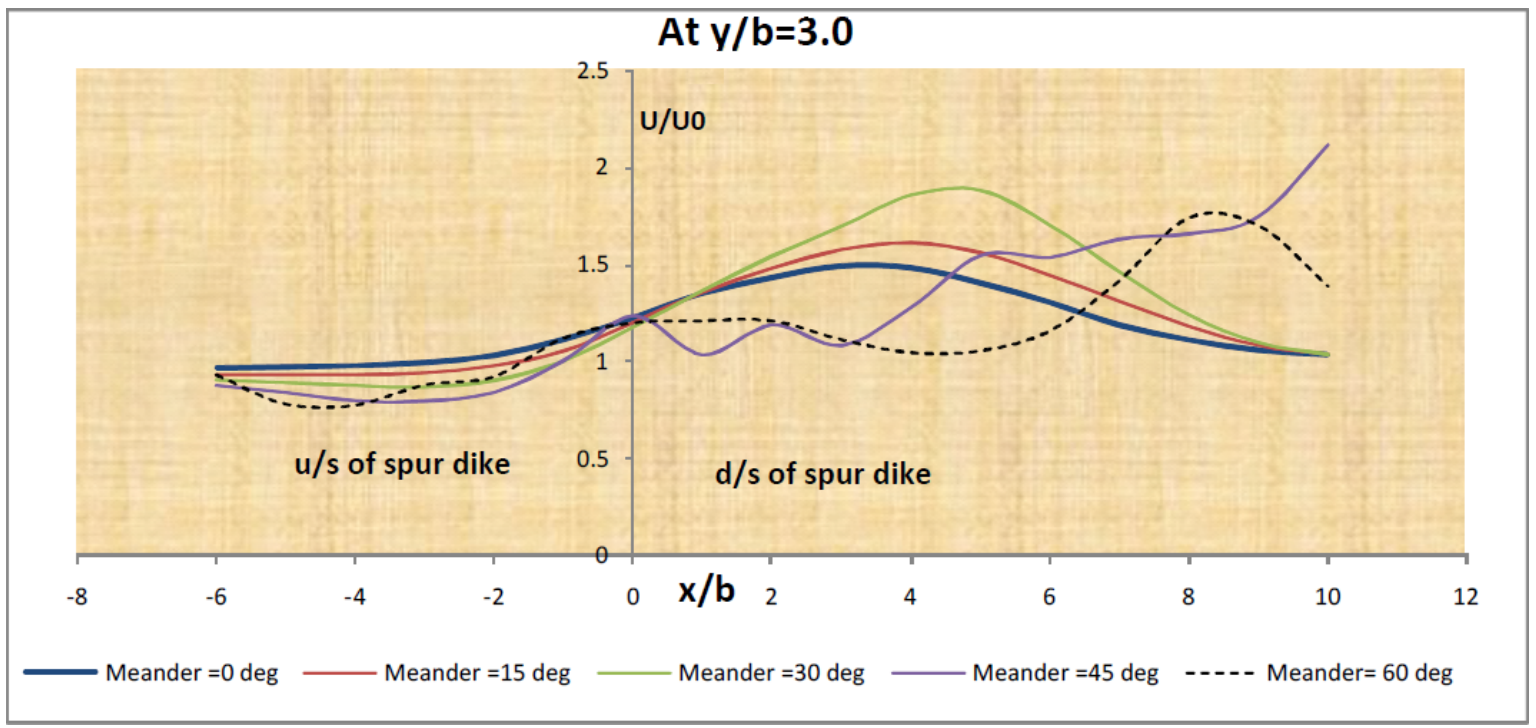

Figure 3.3: Resultant Velocity Profile at $\mathrm{y} / \mathrm{b}=3.0$ 


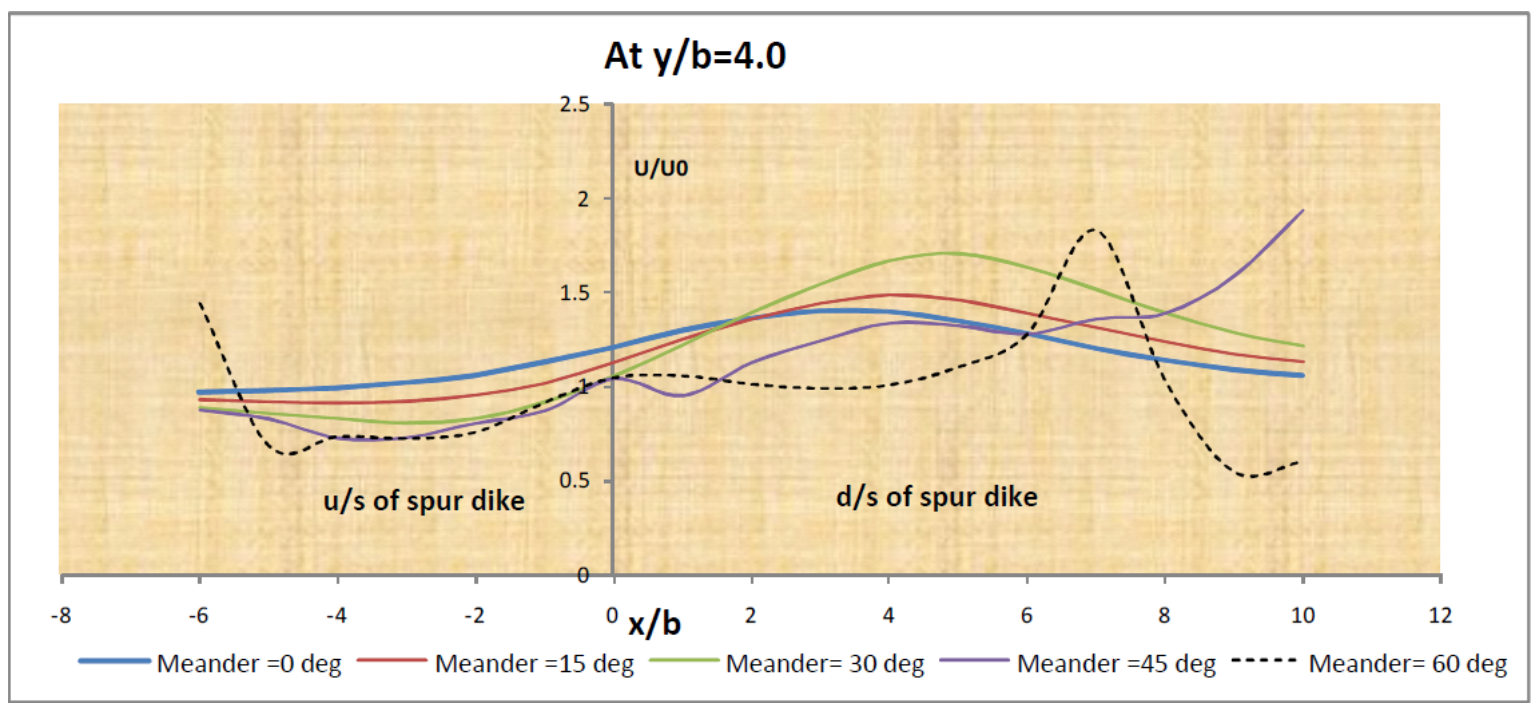

Figure 3.4: Resultant Velocity Profile at $\mathrm{y} / \mathrm{b}=4.0$

\subsection{Flow Separation Zone}

The variation of longitudinal velocity along the width is used to find the boundary of downstream separation zone. Reattachment point i.e end of separation zone is marked where a non-negative value of longitudinal velocity is observed. The variable $\mathrm{W}^{*}{ }_{\max }$ is measured as the maximum width of separation zone and $\mathrm{L}_{2} *$ is the distance of this section from the spur dike position. Results for $\mathrm{L}_{1} *, \mathrm{~L}_{2}{ }^{*}$ and $\mathrm{W}^{*}{ }_{\max }$ for all cases considered are presented in tabular form. Due to its insignificant size, the upstream flow separation zone is not presented here. At the present study the spur dike location was fixed at $\mathrm{s}^{*}=0.5$ from upstream along the right bank. As the meandering angle increases, position of spur dike skews towards downstream considering the position of spur dike on straight channel i.e meandering angle equal to $0^{\circ}$ as reference.

The length and width of separation zone depend upon the angle of meandering and position of spur dike. In the present study, for $\mathrm{s}^{*}=0.5$ the variables $\mathrm{L}_{1} *$ and $\mathrm{W}_{\max } *$ are observed in the range of 9.8 to 12.0 and 2 to 2.8 respectively. It may be recalled that corresponding values in a straight channel were 10.0 to 12.0 and 1.8 to 2.0 respectively. Very interestingly, in the case of meandering angle $60^{\circ}$ spur dike at that position i.e $\mathrm{s}^{*}=0.5$ does not act as flow deflector. Instead, inner apex of the meandering channel (red encircled zone) deflects the flow and works as a deflecting structure in rigid bed with stable bank (Figure 3.9). Moreover, at the starting portion of meandering the outer bank (red encircled zone) also deflects the flow to small extent. It is also observed that except meandering angle $60^{\circ}$, the upstream separation zone is not affected by inflow parameters. However, length and width of downstream separation zone are both slightly affected by flow parameters and angle of meandering.

Table 3.1: Parameters of flow separation zone for different meandering angles

\begin{tabular}{cccccccc}
\hline Case & $\begin{array}{c}\text { Angle of } \\
\text { Meandering } \\
\text { (Degree) }\end{array}$ & Bank & $\begin{array}{c}\text { Spur } \\
\text { dike } \\
\text { location } \\
\left(\mathbf{s}^{*}\right)\end{array}$ & $\begin{array}{c}\mathbf{b} \\
(\mathbf{m})\end{array}$ & $\mathbf{L}_{\mathbf{1}} *$ & $\mathbf{L}_{\mathbf{2}} *$ & $\mathbf{W}_{\mathbf{m a x}}$ \\
\hline 1 & 0 & Right & 0.5 & 0.15 & 10.0 & 3.2 & 2.0 \\
2 & 15 & Right & 0.5 & 0.15 & 9.8 & 3.5 & 2.3 \\
3 & 30 & Right & 0.5 & 0.15 & 12.0 & 4.0 & 2.6 \\
4 & 45 & Right & 0.5 & 0.15 & 10.2 & 3.7 & 2.8 \\
5 & 60 & Right & 0.5 & 0.15 & N/A & N/A & N/A \\
\hline
\end{tabular}

\section{Conclusions}

A numerical study in a fixed bed meandering channel to find the flow field due to various angle of meandering and comparison with straight channel with same parameters was carried out. The main conclusions of this study are outlined as below:

(i) Significance of vertical impermeable spur dike as a flow deflecting structure does not prevail at meandering angle equal or greater than $60^{\circ}$ and position of spur dike at $\mathrm{s}^{*}=0.5$ with reference to the straight rectangular channel from the upstream end on the right bank.

(ii) With the same flow parameters and channel characteristics, the velocity amplification is maximum for angle of meandering equal to $30^{\circ}$ to same position of vertical impermeable 
Velocity Field for Straight Channel ( Meander= 0 deg)

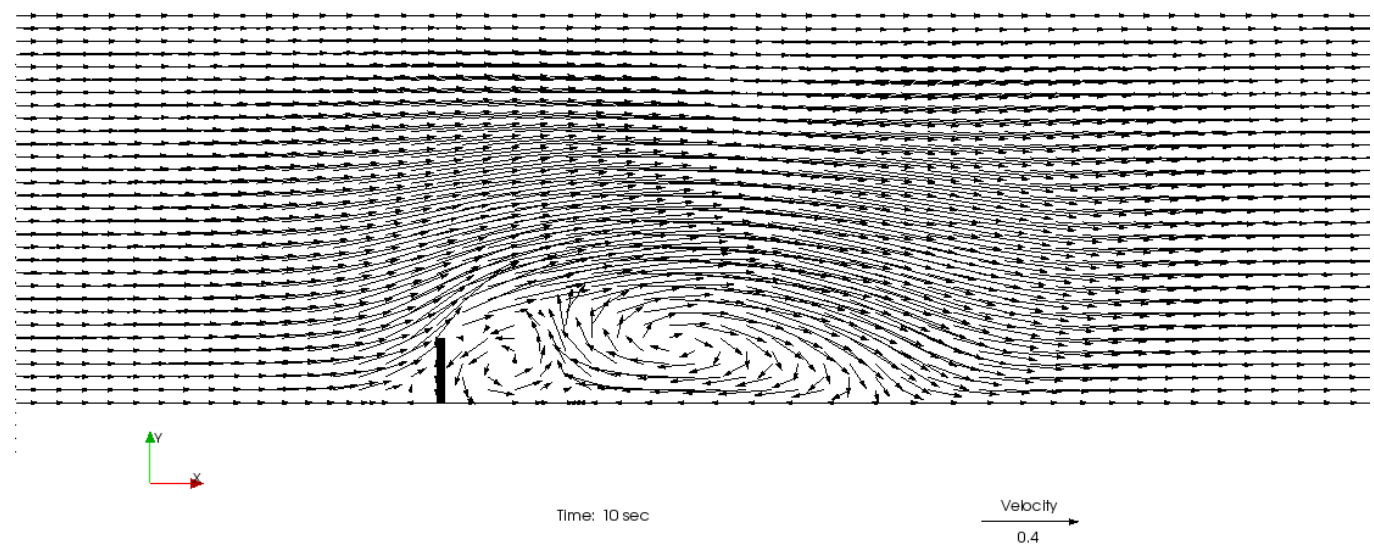

Figure 3.5: Separation Zone for Meandering Angle $=0 \mathrm{deg}$

Velocity Field at Nieander $=15 \mathrm{deg}$

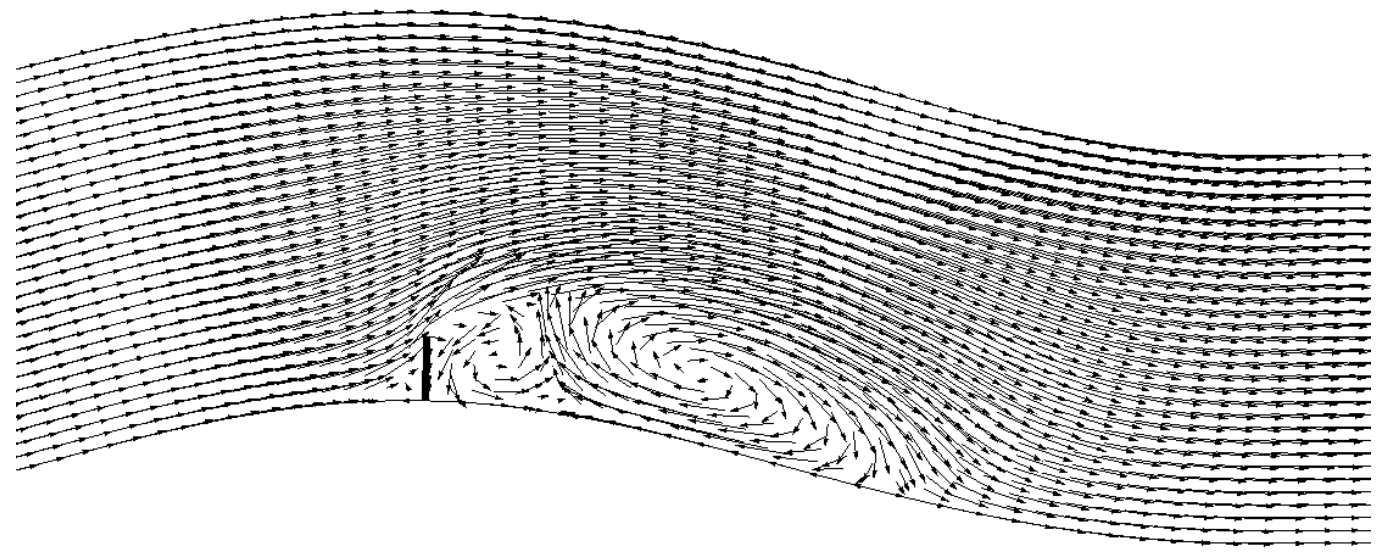

Time: $10 \mathrm{sec}$

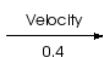

Figure 3.6: Separation Zone for Meandering Angle $=15 \mathrm{deg}$

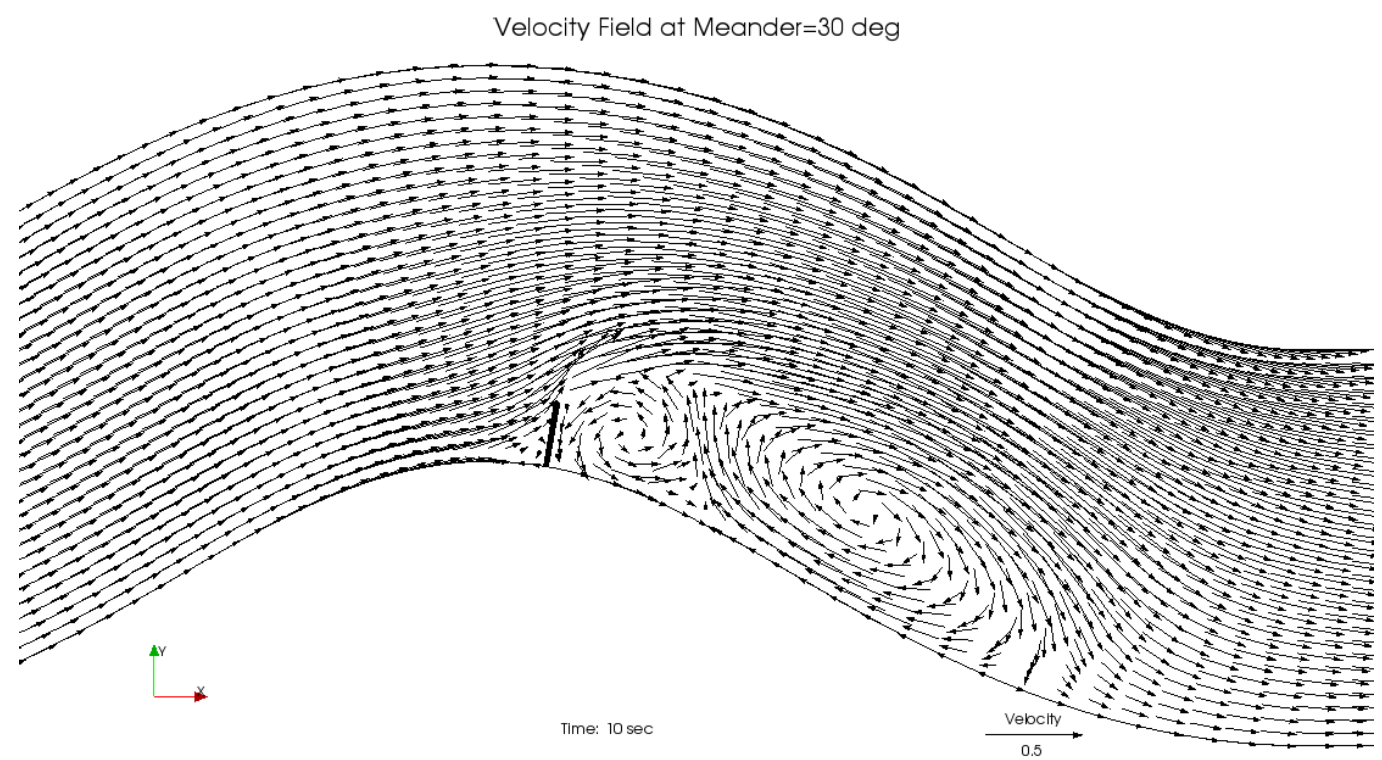

Figure 3.7: Separation Zone for Meandering Angle $=30 \mathrm{deg}$ 


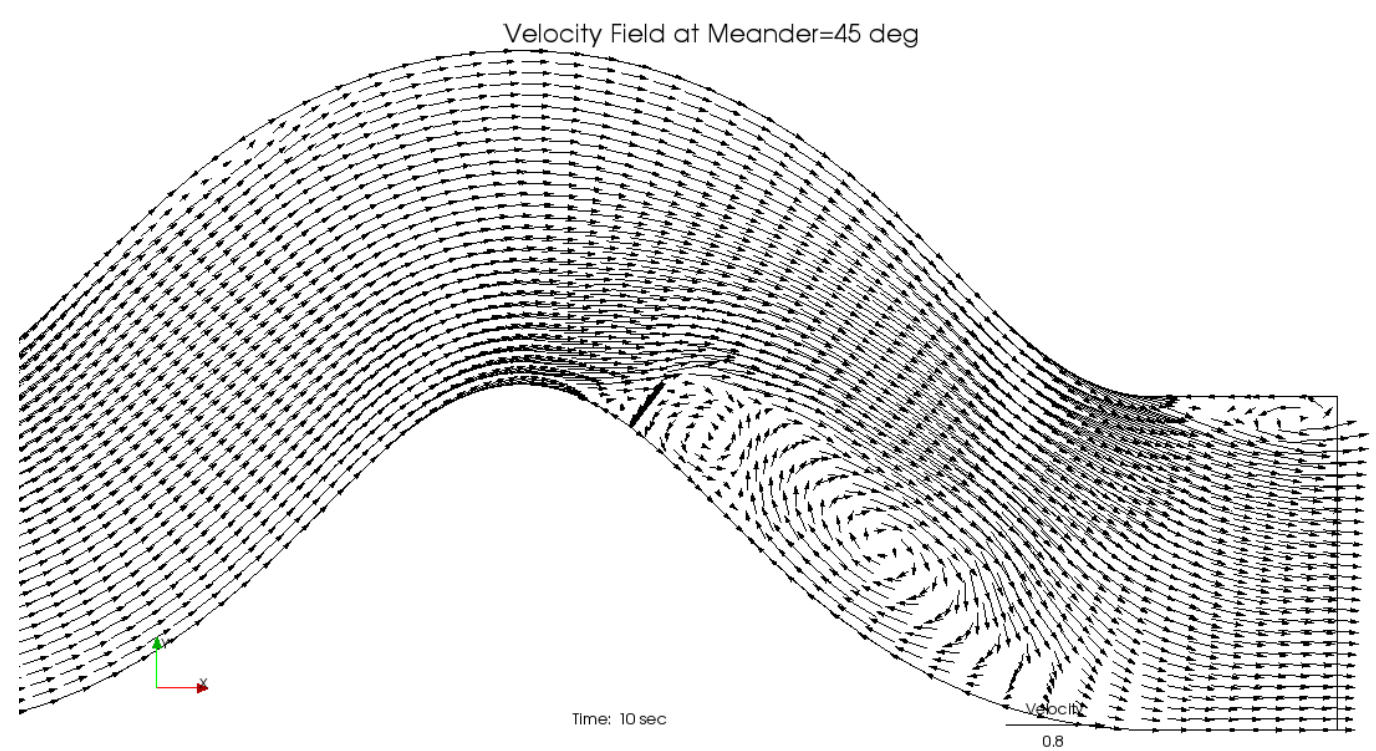

Figure 3.8: Separation Zone for Meandering Angle $=45 \mathrm{deg}$

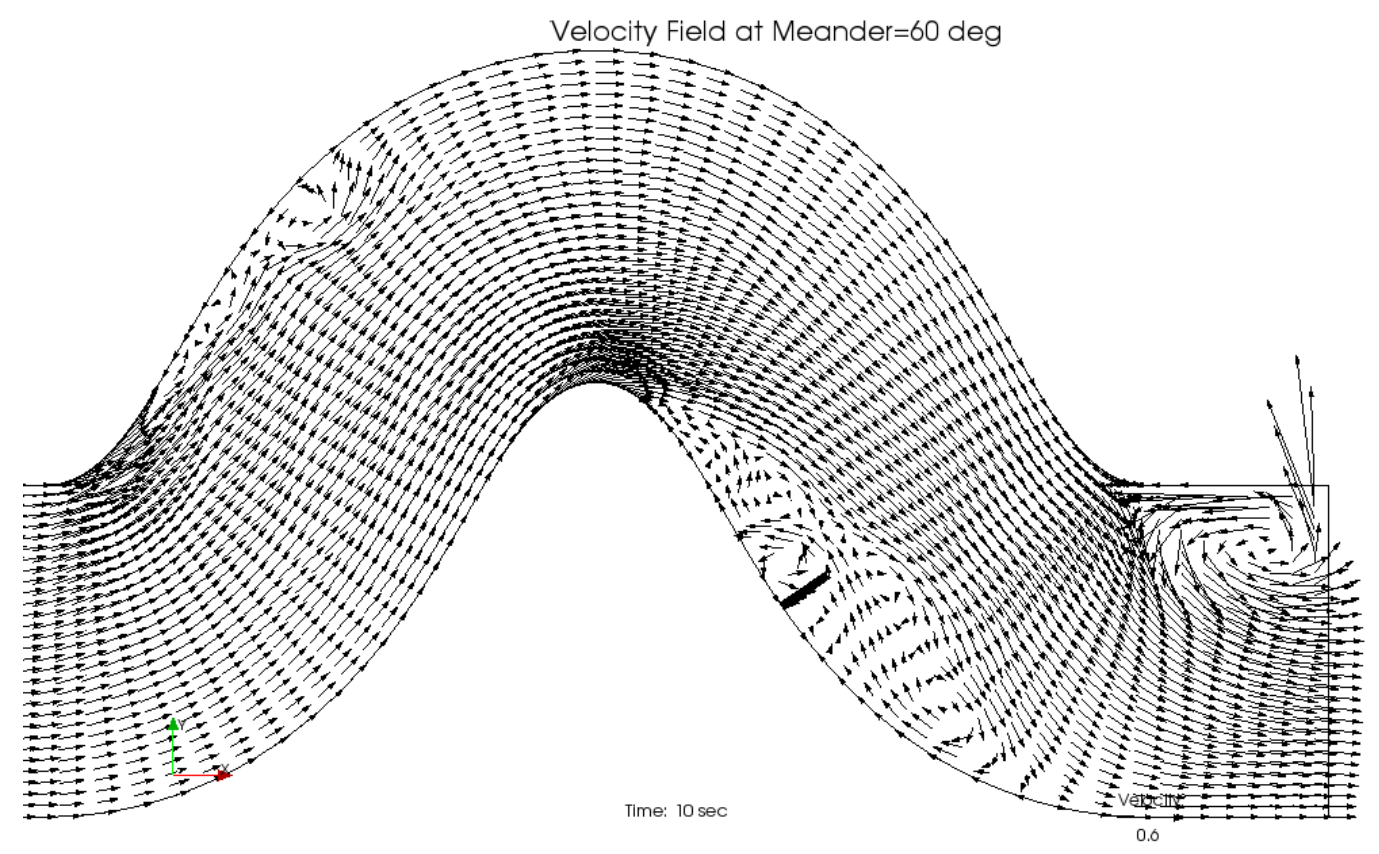

Figure 3.9: Separation Zone for Meandering Angle $=60 \mathrm{deg}$

spur dike along the inner bank compared to meandering angle $0^{\circ}, 15^{\circ}$ and $45^{\circ}$.

(iii) The separation zone parameters, length, maximum width and location of maximum width may vary depending upon the angle of meandering.

(iv) The maximum and minimum non-dimensional downstream flow separation lengths are 12.0 and 9.8 respectively. Maximum and minimum nondimensional width of downstream separation zone is 2.0 to 2.8 .

\section{Notation}

The following notations are used in this paper:

$\mathbf{b}=$ length of spur dike

$\mathbf{L}_{\mathbf{1}}=$ length of downstream separation zone

$\mathbf{L}_{\mathbf{2}}=$ distance between section of maximum width of separation zone and spur dike

$\mathbf{U}=$ resultant velocity in horizontal plane

$\mathbf{U}_{\mathbf{0}}=$ velocity of flow at the beginning of channel 
$\mathbf{S}^{*}=$ non-dimensional distance (ratio of distance of spur dike from upstream end to total length of channel)

$\mathbf{W}_{\max }=$ Maximum width of separation zone

\section{References}

Acharya, A. and Duan, J. G. (2011). Three dimensional simulation of flow field around series of spur dikes, World Environmental and Water Resources Congress 2011: Bearing Knowledge for Sustainability, pp. 2085-2094.

Alvarez, J. A. M. (1989). Design of groins and spur dikes, Proceedings 1989 National Conference on Hydraulic Engineering, New Orleans, pp. 296-301.

Brown, S. A. (1984). Design guidelines for spur-type flow-control structures, Transportation Research Record 950(2).

Ettema, R. and Muste, M. (2004). Scale effects in flume experiments on flow around a spur dike in flatbed channel, Journal of Hydraulic Engineering 130(7): 635-646.

Fei-Yong, C. and Ikeda, S. (1997). Horizontal separation flows in shallow open channels with spur dikes, Journal of Hydroscience and Hydraulic Engineering 15(2): 15-30.

Giri, S., Shimizu, Y. and Surajate, B. (2004). Laboratory measurement and numerical simulation of flow and turbulence in a meandering-like flume with spurs, Flow Measurement and Instrumentation 15(5-6): 301-309.

Koken, M. (2011). Coherent structures around isolated spur dikes at various approach flow angles, Journal of Hydraulic Research 49: 736-743.

Koken, M. and Constantinescu, G. (2008). An investigation of the flow and scour mechanisms around isolated spur dikes in a shallow open channel: 1. conditions corresponding to the initiation of the erosion and deposition process, Water Resources Research 44(8).

Molls, T., Chaudhry, M. H. and Khan, K. W. (1995). Numerical simulation of two-dimensional flow near a spur-dike, Advances in Water Resources 18(4): 227-236.

Nagata, N., Hosoda, T., Nakato, T. and Muramoto, Y. (2005). Three-dimensional numerical model for flow and bed deformation around river hydraulic structures, Journal of Hydraulic Engineering 131(12): 1074-1087.

Ouillon, S. and Dartus, D. (1997). Three-dimensional computation of flow around groyne, Journal of Hydraulic Engineering 123(11): 962-970.

Rajaratnam, N. and Nwachukwu, B. A. (1983). Flow near groin-like structures, Journal of Hydraulic Engineering 109(3): 463-480.

Richardson, E., Stevens, M. and Simons, D. (1975). The design of spurs for river training, Proceeding of the 15th Congress of the International Assosiation for Hydraulic Research (IAHR) Sao Paulo, Brazil, Vol. 2, pp. 382-388.

Sharma, K. and Mohapatra, P. K. (2009). Numerical study of reattachment length for flow past spur dyke in a meandering channel, Proceedings of River Hydraulics 2009, Indian Society for Hydraulics, pp. 124-132.

Sharma, K. and Mohapatra, P. K. (2012). Separation zone in flow past a spur dyke on rigid bed meandering channel, Journal of Hydraulic Engineering 138(10): 897-901.

Shimizu, Y; Nelson, J. (2012). Introduction of Nays solver in iRIC, iRIC. Www.i-ric.org.

Tingsanchali, T. and Maheswaran, S. (1990). 2$\mathrm{d}$ depth-averaged flow computation near groyne, Journal of Hydraulic Engineering 116(1): 71-86.

USACE (1980). USACE Publications - Engineer Manuals.

Yossef, M. M. and Klaassen, G. J. (2002). Reproduction of groynes-induced river bed morphology using les in a 2-D morphological model, River Flow 2002-Proceedings of the Intternational Conference on Fluvial Hydraulics, pp. 1099-1108. 